\title{
Exploração Sexual Comercial de Crianças e Adolescentes: Um Estudo com Caminhoneiros Brasileiros ${ }^{1}$
}

\author{
Normanda Araujo de Morais ${ }^{2}$ \\ Elder Cerqueira-Santos \\ Andreína da Silva Moura \\ Marlene Vaz \\ Sílvia Koller \\ Universidade Federal do Rio Grande do Sul
}

\begin{abstract}
RESUMO - Este artigo busca compreender os condicionantes da exploração sexual de crianças e adolescentes (ESCCA), a partir da percepção de caminhoneiros brasileiros, clientes ou não da ESCCA. Entrevistou-se 239 caminhoneiros em diferentes regiões brasileiras, através de um questionário. As respostas foram categorizadas e analisadas através de estatísticas descritivas (freqüência e média). Os principais condicionantes ressaltados foram a desigualdade social e econômica, a forte cultura de gênero machista e adultocêntrica dos caminhoneiros, assim como a tendência à desresponsabilização pelas crianças e adolescentes abusadas, o seu pouco conhecimento e consideração dos direitos e características desenvolvimentais dessa população. Concluise, ressaltando a relevância de estudos que enfatizam a perspectiva do abusador. Estes podem contribuir para o desvelamento das realidades econômicas, sociais, culturais e políticas envolvidas tanto na formação da demanda quanto da oferta do comércio sexual e, assim, permitir a elaboração de perspectivas de enfrentamento da ESCCA mais eficazes.
\end{abstract}

Palavras-chave:exploração sexual comercial; crianças; adolescentes; caminhoneiros.

\section{Children and Adolescents Commercial Sexual Exploitation: A Study with Brazilian Truck Drivers}

\begin{abstract}
This article aims at understanding the reasons for children and adolescents' commercial sexual exploitation by the perception of brazilian truck drivers, both clients and non clients of this service. Based on a questionnaire, interviews were made with 239 truck drivers in different regions in Brazil. The answers were categorized and analyzed using descriptive statistics (frequency and mean). The main reasons stressed were the social and economic inequality, the strong male chauvinist culture and the drivers' ideas about adulthood as well as the tendency to feel not responsible for the children and adolescents abused and the poor knowledge and consideration for the rights and development characteristics of this population. We may conclude emphasizing the importance of studies which stress the abuser perspective. They may contribute to better understand the economic, social, cultural and political realities involved both in the formation of the demand as well as of the offer of sexual commerce. Based on this information, it could be possible to elaborate more efficient projects to confront this problem.
\end{abstract}

Key words: commercial sexual exploitation; children; adolescents; truck drivers.

A exploração sexual comercial de crianças e adolescentes (ESCCA) é um fenômeno que tem sido descrito em várias partes do mundo. A ESCCA é definida como uma relação de mercantilização e abuso do corpo de crianças e adolescentes por exploradores sexuais, sejam as grandes redes de comercialização local e global, pais/responsáveis ou os consumidores de serviços sexuais pagos (Faleiros, 2000, 2004). Algumas definições como a da Organização Mundial da Saúde (World Health Organization - WHO, 1999) consideram a ESCCA uma forma de abuso contra crianças e adolescentes. Segundo esta organização abuso sexual infantil é:

1 Esta pesquisa foi realizada com o financiamento do Instituto WCF Brasil (World Child Foundation).

2 Endereço: Instituto de Psicologia, UFRGS, Rua Ramiro Barcelos, 2600/104, Porto Alegre, RS, Brasil 90035-006.E-mail: normandaaraujo@ yahoo.com.br
(...) todo envolvimento de uma criança em uma atividade sexual na qual não compreende completamente, já que não está preparada em termos de seu desenvolvimento. Não entendendo a situação, a criança, por conseguinte, torna-se incapaz de informar seu consentimento. (...) Pode incluir também práticas com caráter de exploração, como uso de crianças em prostituição, o uso de crianças em atividades e materiais pornográficos, assim como quaisquer outras práticas sexuais ilegais. (WHO, 1999, p. 6).

A definição fornecida pela WHO é ampla, abrangendo também a ESCCA. De fato, há entre a situação de abuso sexual (intra ou extra familiar) e a situação de exploração sexual comercial, muitos elementos em comum, sobretudo a questão do abuso de poder de um adulto sobre uma criança e/ ou adolescente. No entanto, no caso específico da ESCCA, o caráter comercial é fundamental na sua ocorrência e definição, fato que implica outras peculiaridades à situação do abuso. Algumas dessas particularidades, por exemplo, são percebidas 
na descrição do fenômeno e seus personagens. Nesse sentido, termos como "comércio sexual", "cliente", "emanda" e "oferta" são bastante freqüentes e são muito ilustrativos do poder que o critério econômico tem sobre a situação da exploração sexual comercial de crianças e adolescentes. Diante da situação de marginalização social e econômica em que o nosso país se encontra, portanto, parece bastante relevante o estudo de um fenômeno que é definido a priori como uma situação em que a desigualdade econômica está diretamente relacionada.

A literatura destaca quatro formas de exploração sexual comercial, quais sejam: a pornografia, o turismo sexual, o tráfico para fins sexuais e a "prostituição" (Libório, 2004; Libório \& Martinez, 2002). Sobre esse último termo aqui empregado ("prostituição"), muitas críticas têm sido feitas quanto ao seu uso. Esse termo não é adequado quando se refere a crianças e adolescentes, pois o mesmo relaciona-se a uma parcela de adultos que "escolheu" o comércio do sexo como uma profissão, o que não é o caso de crianças e adolescentes. Opta-se, assim, pela expressão "prostituídas" e "exploradas" a fim de romper com o estereótipo e culpabilização das crianças e adolescentes envolvidas nesse comércio sexual, pois os estudiosos da área reconhecem que há na exploração sexual infantil, uma relação de violência que visa a obtenção de proveito por parte dos adultos, causando danos biopsicosociais às crianças e adolescentes explorados (Faleiros, 2000).

A exploração tanto de crianças quanto de adolescentes pode acontecer de maneira formal ou informal. No mercado formal, crianças e adolescentes são explorados/agenciados diretamente por uma terceira pessoa, que não o cliente final do serviço sexual. Essa terceira pessoa, por sua vez, tem diretos sobre os lucros gerados pelo serviço oferecido pela criança e pelo adolescente. Além disso, neste tipo de mercado há uma relação contratual mais rigorosa entre crianças, adolescentes e clientes. Já no mercado informal, não existe uma terceira pessoa que agencia os serviços, com as crianças e adolescentes oferecendo esses serviços sexuais autonomamente. Contudo, muitas vezes, pode haver uma exploração indireta por partes de cafetões ou de parceiros abusivos que podem obter ganhos eventuais com os serviços sexuais oferecidos. A relação entre clientes no mercado informal é menos rígida. Muitas vezes, não há clara demanda de recompensa financeira em troca dos serviços sexuais, havendo, por exemplo, a expectativa de casamento com o cliente por parte de quem oferece o serviço. Além disso, a relação entre o "prostituído" e o cliente, muitas vezes não é apenas eventual, perdurando por um período mais longo. No mercado informal, quem oferece os serviços sexuais não se auto-denomina como prostituta, o que pode atuar como facilitador para aqueles homens que não desejam ser vistos como "clientes" deste tipo de serviço (Davidson \& Taylor, 1996). Essa classificação foi feita com base em estudos realizados em diferentes países ao redor do mundo, inclusive em países da América Latina.

A visibilidade da ESCCA no Brasil ocorreu a partir da década de 1990, com a realização da Comissão Parlamentar de Inquérito (CPI) que investigou as denúncias do comércio sexual envolvendo menores de 18 anos de idade (Libório, 2003). A análise dos depoimentos dessa CPI mostrou que os caminhoneiros são um dos principais personagens envolvidos no fenômeno da ESCCA, juntamente com os pais das crianças e adolescentes explorados, os policiais e donos de boates
(Gomes, Minayo \& Fontoura, 1999). Embora os depoimentos tenham mostrado que os caminhoneiros são clientes em potencial do comércio sexual com crianças e adolescentes, fato que ocorre em outros países tais como a Venezuela, por exemplo (Davidson \& Taylor, 1996), não se encontra na literatura nenhum estudo que evidencie e esclareça tal relação. Ao mesmo tempo, também há na literatura uma grande lacuna de estudos acerca da temática da exploração sexual, principalmente a respeito dos abusadores sexuais (Marques, 2005). Os estudos mais recentes abordam a problemática e até mapeiam o fenômeno de maneira detalhada e focalizada, como é o caso do Relatório PESTRAF (Leal \& Leal, 2002), que destaca o perfil das meninas e mulheres vítimas do tráfico humano com fins de exploração sexual no Brasil. Porém, persiste a lacuna quanto ao outro lado da dinâmica de exploração: o cliente (abusador).

O presente artigo busca, portanto, compreender os condicionantes da exploração sexual de crianças e adolescentes a partir da percepção de caminhoneiros brasileiros, clientes ou não da ESCCA. Para isso, serão analisadas: 1) a definição sobre crianças e adolescentes; 2) quais os principais motivos que levariam crianças e adolescentes a se "prostituírem"; 3) quais os motivos pelos quais alguns homens preferem fazer sexo com crianças/adolescentes; e, 4) quais os motivos pelos quais alguns caminhoneiros afirmam não terem saído com crianças/adolescentes.

Entender o modo como estes caminhoneiros percebem as crianças e adolescentes abusadas, bem como a situação de exploração sexual na qual estas se encontram pode ser um fator importante para a compreensão do modo como eles se relacionam com elas. Esta compreensão pode elucidar, pelo menos em parte, os motivos pelos quais os participantes se envolvem com a ESCCA, tanto como clientes ou como "auxiliares" nesta atividade.

Trata-se, de acordo com Santos (2004), de entender o fenômeno da ESCCA a partir da perspectiva do abusador e não mais somente da perspectiva da vítima, ou seja, da criança e adolescente abusada/explorada. Entende-se, assim, que tão importante quanto perguntar a uma criança/adolescente ou a outras pessoas o porquê delas se "prostituírem" é perguntar o porquê de algumas pessoas preferirem fazer sexo e/ou serem clientes do comércio sexual de crianças e adolescentes. Nesse sentido, não se está responsabilizando as crianças e adolescentes por sua condição, mas implica-se, desde o início, o lado dos adultos que criam e alimentam a demanda por esse tipo de serviço. Na lógica comercial, para que uma relação comercial seja efetivada, são necessários tanto o produto a ser vendido quanto o comprador interessado. Nesse sentido, mesmo que uma criança/adolescente esteja disposta a oferecer-se sexualmente em troca de dinheiro ou favores outros (alimento, roupa, carona etc.), se não houvesse quem estivesse disposto a comprar tal serviço, a situação de exploração sexual não se estabeleceria.

\section{Método}

\section{Participantes}

A composição total da amostra consistiu de 239 caminhoneiros brasileiros (todos do sexo masculino) que residem ou 
estiveram de passagem, no período de outubro a dezembro de 2004, pelas seguintes cidades do Brasil: Porto Alegre e Alegrete, RS, Itajaí, SC, Cubatão e Santos, SP, Belém, PA, Natal, RN e Aracaju, SE.

\section{Instrumento}

Foi utilizado um questionário especialmente produzido para este estudo. O instrumento contava de 60 questões (abertas e de múltipla escolha), que abordavam temas relacionados aos objetivos do estudo (aspectos biossociodemográficos, caracterização da profissão, uso de drogas e vida sexual, conhecimento sobre a prostituição nas estradas, exploração sexual comercial de crianças e adolescentes e sobre os direitos destes). Ao final do instrumento, havia uma folha de registro a ser preenchida pelo entrevistador com suas impressões sobre o participante e relatos importantes sobre a temática da exploração sexual de crianças e adolescentes. Neste estudo, foram analisadas quatro tópicos em especial: 1) concepção de infância e adolescência, 2) principais motivos relacionados à ESCCA, 3) principais motivos pelos quais alguns homens preferem fazer sexo com crianças e/ou adolescentes e 4) principais motivos pelos quais alguns caminhoneiros afirmaram não ter saído com crianças/ adolescentes.

\section{Procedimentos}

O processo de coleta de dados teve como base a metodologia da Inserção Ecológica, descrita e proposta por Cecconello e Koller (2003) para o estudo do desenvolvimento-no-contexto. De acordo com essa perspectiva, os pesquisadores inseremse no ambiente de pesquisa a fim de estabelecer uma relação de maior proximidade com o seu objeto de estudo e, assim, responder às questões de pesquisa. Nesse sentido, tão importante quanto os dados das próprias entrevistas realizadas, são as anotações feitas em diários de campo elaborados pelos pesquisadores acerca dos diversos momentos de interação com as diferentes pessoas no contexto estudado.

Os participantes foram entrevistados por um membro da equipe de pesquisa (psicólogo ou estudante da graduação do curso de Psicologia ${ }^{3}$ ) que anotava as respostas dos entrevistados. As entrevistas duraram, em média, 40 minutos e foram realizadas em postos de gasolina ou pátios de parada dos caminhoneiros. Todos os locais nos quais a coleta de dados foi realizada foram sugeridos pelos próprios caminhoneiros como sendo os locais preferidos por eles para parada, espera de carga e descanso. Além disso, as cidades escolhidas para a coleta representam pontos estratégicos de circulação de muitos caminhoneiros, uma vez que cortam as principais rodovias do país. Objetivou-se, assim, abranger diferentes contextos e rotas freqüentadas pelos participantes.

Os caminhoneiros foram abordados quando estavam conversando com colegas, caminhando sozinhos ou em pequeno grupo. Evitou-se incomodá-los nos seus horários de refeição

3 Todos os estudantes/entrevistadores eram do sexo masculino e foram treinados teórica e metodologicamente para este estudo. Apenas uma das coordenadoras da pesquisa foi do sexo feminino. e quando estavam envolvidos em alguma outra atividade (limpeza e conserto do caminhão, por exemplo). A amostragem foi por conveniência e o número total de participantes entrevistados foi definido a partir do critério de saturação dos dados, ou seja, em reuniões periódicas os pesquisadores perceberam a repetição dos dados e decidiram interromper a coleta.

Concluída a aplicação do questionário, o entrevistador preenchia a folha de registros, anexa ao questionário. Nesta folha, ele escrevia suas impressões sobre o participante (confiabilidade, disponibilidade em participar etc), questões referentes ao seu conhecimento e/ou uso de serviços de exploração sexual comercial de crianças e adolescentes, dentre outras informações que julgasse relevante à pesquisa.

\section{Questões éticas}

Os aspectos éticos que garantem a integridade dos participantes deste estudo foram assegurados, com base na Resolução $\mathrm{n}^{\circ} 196$ que consiste em diretrizes e normas que regulam as pesquisas com os seres humanos (Conselho Nacional de Saúde, 1996) e na Resolução $n^{\circ} 016$ do Conselho Federal de Psicologia (CFP, 2000). Além do Termo de Consentimento Livre e Esclarecido, foi disponibilizada a assistência do membro da equipe de pesquisa, caso algum participante necessitasse de apoio psicológico provocado pela lembrança negativa de algum dos aspectos investigados.

A coleta era iniciada somente após a explicação dos objetivos e do consentimento dos caminhoneiros em participar da pesquisa. Desde o primeiro contato com o participante foi garantida ao mesmo a compreensão das características da pesquisa e dos seus direitos como respondente, inclusive o caráter voluntário da participação e o sigilo das informações. A pesquisa recebeu, ainda, a aprovação do Comitê de Ética em Pesquisa da Universidade Federal do Rio Grande do Sul.

\section{Resultados e Discussão}

Foram entrevistados 239 caminhoneiros nos estados do Rio Grande do Sul $(n=86 ; 36,6 \%)$, Santa Catarina $(n=64 ; 27,2 \%)$, São Paulo $(n=25 ; 10,6 \%)$, Rio Grande do Norte $(n=20 ; 8,5 \%)$, Sergipe $(n=20 ; 8,5 \%)$ e Pará $(n=20 ; 8,5 \%)$. A distribuição desigual das entrevistas aconteceu devido ao tempo dedicado à coleta de dados em cada uma dessas cidades. Em geral, os participantes não residiam nessas cidades, o que proporcionou uma amostra de homens que residem em quase todos os estados do Brasil, excluindo-se apenas Acre e Roraima.

\section{Caracterização sociodemográfica}

A média de idade dos participantes foi de 38,26 anos $(D P=10,20)$. Do total da amostra, $69,0 \%$ disseram ser casados ou ter um relacionamento estável com uma companheira. A média de idades destas foi de 36,10 anos $(D P=9,89)$. Mais de $70 \%$ dos caminhoneiros $(74,1 \%)$ têm filhos, sendo que a média de filhos foi de $1,47(D P=1,36)$.

A maioria dos participantes $(64,0 \%)$ declarou ser "branco", seguido pelos "mestiços" (33,1\%) e "negros" $(2,9 \%)$. Quanto à escolaridade, a maioria dos caminhoneiros $(32,8 \%)$ cursou apenas o ensino fundamental incompleto, sendo que somente $19,7 \%$ concluiu o ensino médio e $23,9 \%$ concluiu o ensino 
fundamental. A renda média mensal familiar é de R \$1001,00 a $\mathrm{R} \$ 2000,00$ para $55,3 \%$ dos caminhoneiros e de mais de $\mathrm{R} \$$ 2000,00 para 32,5\% deles. No geral, os caminhoneiros entrevistados mostraram-se satisfeitos com o valor da sua renda mensal, pois acreditavam que em nenhuma outra profissão conseguiriam uma renda equivalente ou superior, dada a sua baixa escolaridade (fundamental incompleto).

Em seguida, são descritos os principais resultados da pesquisa, no que se refere aos seus objetivos: 1) a definição de infância e adolescência; 2) quais os principais motivos que levariam crianças e adolescentes a se "prostituírem"; 3 ) quais os motivos pelos quais alguns homens preferem fazer sexo com crianças/adolescentes; e, 4) quais os motivos pelos quais alguns caminhoneiros afirmam não terem saído com crianças/adolescentes. Durante a descrição dos resultados, o termo "prostituição" será utilizado, pois as perguntas feitas aos caminhoneiros usaram esta expressão. Optou-se pela utilização desta palavra, pois "exploração sexual de crianças e adolescentes" poderia ser pouco familiar para os participantes. Além disso, o termo "exploração" poderia soar de forma negativa para os caminhoneiros, ocasionando assim algumas resistências para a participação na pesquisa, assim como a idéia de culpabilização e julgamento.

\section{Definição de infância e adolescência}

Durante a entrevista, algumas questões sobre a definição de infância e adolescência foram feitas aos caminhoneiros. A Tabela 1 compara as médias atribuídas pelos caminhoneiros ao grau de importância que atividades como estudar, brincar, ficar com a família, namorar etc. têm para crianças e adolescentes. Os valores variavam de 1-5.

Comparando-se as médias atribuídas a crianças e adolescentes, as atividades de estudar, brincar, ficar com a família, ter amigos e passear são vistas como mais características da

Tabela 1. Média dos Índices do Grau de Importância Atribuída Pelos Caminhoneiros às Atividades de Estudar, Brincar, Trabalhar, Ficar com a Família, Ter Amigos, Passear, Fazer Sexo e Namorar na Vida de Crianças e Adolescentes.

\begin{tabular}{lcccc}
\hline \multirow{2}{*}{ Atividades } & \multicolumn{2}{c}{ Criança } & \multicolumn{2}{c}{ Adolescente } \\
& Média & DP & Média & DP \\
\cline { 2 - 5 } Estudar & 4,99 & 0,09 & 4,92 & 0,38 \\
Brincar & 4,92 & 0,40 & 3,78 & 1,1 \\
Trabalhar & 1,55 & 1,10 & 3,6 & 1,24 \\
Ficar com a família & 4,94 & 0,32 & 4,89 & 3,4 \\
Ter amigos & 4,77 & 0,60 & 4,61 & 0,79 \\
Passear & 4,67 & 0,71 & 4,44 & 0,87 \\
Fazer sexo & 1,04 & 0,31 & 2,61 & 1,38 \\
Namorar & 1,17 & 0,61 & 3,37 & 1,36 \\
\hline
\end{tabular}

infância que da adolescência. Já as atividades de trabalhar, fazer sexo e namorar foram relatadas como mais típicas dos adolescentes que das crianças. As respostas dos participantes para esta pergunta, portanto, coincidem com o que é aceito socialmente para as fases da infância e da adolescência.

Com relação à questão da idade apropriada para o começo da vida sexual dos adolescentes, os caminhoneiros destacaram que a idade média adequada para um adolescente do sexo masculino iniciar a vida sexual é 16 anos $(D P=1,90)$, enquanto que para o sexo feminino a idade média é um pouco superior $(M=18$ anos; $D P=1,81)$. No entanto, a infância e adolescência a qual os caminhoneiros fazem referência nessa resposta, parece ser a infância e adolescência de suas próprias filhas, sobrinhas e netas, por exemplo. A infância e a adolescência das crianças e adolescentes exploradas sexualmente nas estradas e locais de parada por onde passam, por sua vez, aparenta ser determinada por outro critério diferente da idade.

Em vários momentos da entrevista, nos quais eram mencionados os termos "crianças" e "adolescentes", os caminhoneiros perguntaram aos entrevistadores a qual faixa etária se estava fazendo referência. Embora a concepção de criança/adolescente que orientou essa pesquisa seja a do Estatuto da Criança e do Adolescente (ECA, 1990) $)^{4}$, procurou-se não influenciar os participantes com os critérios da própria pesquisa. Dessa forma, estimulou-se que os participantes dissessem, eles mesmos, o que caracterizava cada faixa etária. Percebeu-se que os caminhoneiros tenderam a encurtar o período da infância, assim como a adolescência, sobretudo quando buscavam legitimar o "trabalho infantil" e o "sexo com adolescentes". No caso do trabalho infantil, muitas vezes, os participantes legitimaram o fato de uma criança poder trabalhar com a justificativa de que eles mesmos trabalharam na sua infância para ajudar suas famílias e disso não ter prejudicado o seu desenvolvimento.

Quanto à prática de sexo com menores de 18 anos, vale destacar que entre os 239 caminhoneiros entrevistados, 85 (36,8\%) afirmaram já ter saído com alguma criança/adolescente. Neste caso, a questão da idade tendeu a ser ainda mais relativizada pelos caminhoneiros. Estes tenderam a justificar sua atitude ou de colegas seus com o argumento de que seria impossível saber a real idade das adolescentes, uma vez que elas mentem quando perguntadas ("Ela mentiu a idade.") ou aparentam ser mais velhas do que de fato são ("Ela parecia mulher. Era gostosa."; "Ela tinha 17 anos, mas parecia mais.").

A grande questão, porém, é que a idade "objetiva e cronológica" das meninas exploradas sexualmente não parece ser uma preocupação dos clientes que com elas saem. De acordo com Davidson (2001), a falta de preocupação com a idade das adolescentes representa uma característica comum aos clientes da ESCCA. Nessa pesquisa, muitos caminhoneiros afirmaram que não fazem a pergunta sobre a idade das crianças/adolescentes ("Ele não sabia a idade dela, mas não perguntou. Um colega disse que podia dar problemas." - relato do entrevistador). Além do mais, como se pode inferir das frases mencionadas, mesmo sabendo que a adolescente está mentindo a sua idade, os caminhoneiros não deixam de fazer o programa. Portanto, pode-se concluir que sua preocupação inicial em perguntar aos entrevistadores a que faixa etária corresponde a infância e adolescência é somente uma tentativa de justificar a sua conduta, tornando-a mais socialmente aceitável. Outros argumentos, para além da idade objetiva/cronológica, parecem estar influenciando muito mais decisivamente o fato de um caminhoneiro decidir sair ou não com crianças e adolescentes. Alguns destes outros

4 De acordo com o ECA, são considerados crianças as pessoas até 12 anos de idade incompletos e adolescentes aquelas entre 12 e 18 anos. Em especial, criança e adolescente são reconhecidos na sua condição especial de pessoas em desenvolvimento. 
argumentos serão expostos na descrição das respostas de "por que alguns homens preferem manter relações sexuais com crianças e adolescentes?".

\section{Principais motivos relacionados à exploração sexual de crianças e adolescentes}

Quando perguntados sobre os motivos pelos quais uma criança ou adolescente se "prostituiria", os caminhoneiros (que relataram já ter saído e que não saíram) destacaram as seguintes categorias descritas na Tabela 2.

O critério de necessidade financeira foi o principal motivo citado pelos caminhoneiros para que crianças e adolescentes se "prostituam". Nesse sentido, eles destacaram as regiões Nordeste e Norte (tradicionalmente regiões mais pobres do país) e os estados da Bahia, Maranhão e Pará como sendo os locais onde mais verificam a existência da exploração sexual comercial infantil. Os caminhoneiros destacaram, ainda, que quanto mais pobre a região do país, mais barato se cobra e se paga às

Tabela 2. Frequiência e Porcentagem dos Principais Motivos Relacionados à Prostituição de Crianças e Adolescentes na Percepção dos Caminhoneiros Entrevistados.

\begin{tabular}{lcc}
\hline Categorias & $\begin{array}{c}\text { Freqüiência } \\
\text { (n) }\end{array}$ & $\begin{array}{c}\text { Percentual } \\
(\%)\end{array}$ \\
\hline $\begin{array}{l}\text { Necessidade financeira } \\
\text { (criança e família) }\end{array}$ & 180 & 39 \\
São exploradas/obrigadas por alguém & 72 & 15,6 \\
Elas gostam de sexo/têm prazer & 59 & 12,8 \\
É o que há disponível para fazer & 48 & 10,4 \\
Problemas na família & 39 & 8,4 \\
Uso de drogas & 19 & 4,1 \\
Falta de educação/orientação & 14 & 3,0 \\
Há mercado fácil para eles & 14 & 3,0 \\
Adultos gostam e procuram & 09 & 2,0 \\
Outros & 08 & 1,7 \\
Total & 462 & 100 \\
\hline
\end{tabular}

crianças e adolescentes exploradas. Nas regiões Nordeste e no Norte, portanto, os preços são menores do que nas regiões Sul e Sudeste ("Ah, é o preço de um almoço"). A "falta de opção e perspectiva de vida" como motivadora para a inserção de crianças e adolescentes no comércio sexual também foram destacadas pelos participantes nas seguintes categorias: "são exploradas/ obrigadas por alguém" (seja algum familiar ou as "cafetinas", por exemplo) e "é o que há disponível para fazer".

Outras respostas relacionaram a prostituição infantil à presença de alguma "disfunção", seja através de problemas familiares, uso de drogas ou da falta de educação/orientação. Esta última categoria foi entendida como "falta de princípios e valores morais" e não como "falta de educação formal/escolar". No caso do uso de drogas, a prostituição seria a fonte de renda para a manutenção do uso. Um pequeno percentual de respostas atribuiu o comércio sexual infantil a um "mercado" e a uma "demanda" que existe por esse serviço por parte de alguns homens que fazem sexo com crianças e adolescentes. Essas respostas foram as únicas que relacionaram o comércio sexual infantil com a existência de uma "demanda" por esse serviço, fato que é quase sempre negligenciado na compreen- são do fenômeno da ESCCA. Esta tem sido tradicionalmente compreendida a partir dos fatores que motivam a formação da "oferta" dos serviços sexuais, ou seja, pela resposta à pergunta: “Por que meninas se prostituem?", bem como pela investigação de apenas uma das partes envolvidas nesse processo, que é a menina ou adolescente explorada.

A categoria que afirma que crianças e adolescentes se prostituem porque "gostam de sexo e têm prazer" também foi mencionada. Ela foi a terceira categoria mais citada e é bastante elucidativa do preconceito e culpabilização com que as crianças e adolescentes prostituídas são vistas. Tal concepção representa, ainda, o desconhecimento e/ou naturalização de alguns importantes condicionantes do fenômeno, quais sejam: a realidade sócio-econômica de pobreza em que essas crianças e adolescentes vivem, os valores sociais de gênero, padrões de beleza e as motivações relacionadas à formação da "demanda" pelos homens que são clientes do comércio sexual infantil.

\section{Principais motivos pelos quais alguns homens preferem fazer sexo com crianças e/ou adolescentes}

Com relação a essa última dimensão (formação da “demanda"), incluiu-se no questionário uma questão sobre quais seriam os motivos pelos quais alguns homens preferem fazer sexo com crianças/adolescentes. A Tabela 3 apresenta as principais respostas dos caminhoneiros entrevistados acerca das motivações pelas quais alguns homens preferem fazer sexo com crianças e adolescentes.

A busca de excitação e prazer foi a resposta mais citada. No entender dos caminhoneiros entrevistados, esse prazer está quase sempre relacionado ao padrão de beleza da juventude, hegemônico na sociedade, mídia e também entre eles ("Menina nova dá mais tesão. É mais gostosa."). A "fantasia/ curiosidade", categoria que também está relacionada à busca de maior excitação e prazer sexual foi mencionada como um fator que faz com que alguns homens prefiram fazer sexo com crianças e adolescentes.

As respostas "sentir-se poderoso/reafirmar a masculinidade" e "aumentar a auto-estima" foram bastante citadas e são

Tabela 3. Freqüência e Porcentagem dos Motivos pelos quais Alguns Homens preferem Fazer Sexo com Crianças/Adolescentes na Percepção dos Caminhoneiros Entrevistados.

\begin{tabular}{lcc}
\hline Categorias & $\begin{array}{c}\text { Freqüência } \\
\text { (n) }\end{array}$ & $\begin{array}{c}\text { Percentual } \\
(\mathbf{\%})\end{array}$ \\
\hline Por ter mais excitação e prazer & 118 & 36,3 \\
$\begin{array}{l}\text { "Safadeza, falta de vergonha na cara, } \\
\text { doença" }\end{array}$ & 70 & 21,5 \\
$\begin{array}{l}\text { Sentir-se poderoso/reafirmar } \\
\text { masculinidade }\end{array}$ & 51 & 15,7 \\
Aumentar auto-estima & 24 & 7,4 \\
Oferta (disponibilidade, baixo preço) & 16 & 4,9 \\
Fantasia/Curiosidade & 14 & 4,3 \\
Não sabe & 13 & 4,0 \\
Carência afetiva/necessidade fisiológica & 08 & 2,2 \\
Falta de responsabilidade/respeito à & 07 & 2,2 \\
família & 05 & 1,5 \\
Outros & 326 & 100 \\
Total & & \\
\hline
\end{tabular}


elucidativas de uma concepção de gênero bastante machista desse grupo social. Embora não exclusiva dos caminhoneiros, esse machismo atribui maior valor e "respeito" aos homens que são capazes de seduzir e manter relações com um maior número de mulheres e, de preferência, com mulheres mais jovens que eles e que se enquadrem no padrão de beleza socialmente aceitável (Desouza, Baldwin, Koller \& Narvaz, 2004; Narvaz, 2005). Dado que esse é o padrão de comportamento esperado socialmente, um homem que o consegue atingir, tende a sentirse mais poderoso e com uma auto-estima maior. Por isso que um percentual considerável de respostas atribuiu à busca dessas características o fato de alguns homens preferirem fazer sexo com crianças/adolescentes.

Uma outra concepção naturalizada sobre a prática sexual de homens com crianças e adolescentes atribui à "carência afetiva/necessidade fisiológica" a justificativa para tal comportamento. Nesse caso, a solidão da vida nas estradas, a distância da família e da esposa/companheira, assim como a grande "oferta" de serviços sexuais (grande disponibilidade e baixo preço cobrado) são motivadores para sua atitude, tal como descrito a seguir: "Elas se oferecem. Eu estou carente e aceito."

A categoria "safadeza, falta de vergonha na cara, doença" foi a segunda categoria mais citada. Ela representa uma visão de que a prática sexual com crianças e adolescentes é algo moralmente incorreto e, portanto, reprovável. Outro pequeno percentual de respostas relacionou a prática sexual com crianças e adolescentes à "falta de responsabilidade e respeito" para com a própria família.

\section{Principais motivos pelos quais alguns caminhoneiros afirmaram não ter saído com crianças/adolescentes}

A Tabela 4 apresenta as justificativas dadas por alguns caminhoneiros para o fato de nunca terem saído com crianças/ adolescentes.

Para os caminhoneiros que afirmaram nunca ter saído com menores de 18 anos, o principal motivo alegado foi "saber que é errado", ilustrado em frases como: "Nunca achei certo. Não faço e não valorizo quem faz." e "É um horror fazer isso." Outra resposta elucidativa de uma concepção fortemente moral sobre a prática de sexo com menores de idades é representada

Tabela 4. Freqüência e Porcentagem dos Principais Motivos pelos quais Alguns Caminhoneiros Afirmaram não ter Saído com Crianças/ Adolescentes

\begin{tabular}{lcc}
\hline Categorias & $\begin{array}{c}\text { Freqüência } \\
(\mathbf{n})\end{array}$ & $\begin{array}{c}\text { Percentual } \\
(\boldsymbol{\%})\end{array}$ \\
\hline Sabe que é errado/é contra & 38 & 20,8 \\
Evitar problemas com a justiça & 34 & 18,6 \\
Não tem tesão & 33 & 18,0 \\
Respeito por elas serem “menores”/são & & \\
como as filhas e netas & 33 & 18,0 \\
Respeito à esposa/fidelidade & 23 & 12,6 \\
Não teve oportunidade & 11 & 6,0 \\
Medo de doenças & 06 & 3,3 \\
Medo de ser difamado/falta de coragem & 05 & 2,7 \\
Total & 183 & 100 \\
\hline
\end{tabular}

pela categoria "medo de ser difamado/falta de coragem". Diante da rejeição da sociedade por esse tipo de comportamento, alguns caminhoneiros relataram essa justificativa para nunca terem saído com crianças/adolescentes.

A segunda categoria mais citada entre os participantes refere-se à preocupação de "evitar problema com a justiça" ("Dá problema, encrenca, cadeia.", "É problema na certa. Chave de cadeia.", "Tenho medo de ser pego."). Entre os caminhoneiros, a polícia tem uma representação bastante negativa, sendo constantemente citada como corrupta. Muitos caminhoneiros, inclusive, relataram a associação de policiais com as meninas que se prostituem. De acordo com os caminhoneiros, os policiais forjavam um flagrante quando os caminhoneiros estavam com as meninas, a fim de extorquir o seu dinheiro. Além disso, quando perguntados sobre a experiência de terem saído com menores de idade, o medo da polícia foi novamente citado. Dessa vez, para justificar o porquê de tal experiência não ter sido boa ("Foi sem graça. Fiquei preocupado com a polícia.”).

Assim como a busca de excitação e prazer foi mencionada como uma motivação para que alguns homens prefiram fazer sexo com menores de idade, a "falta de tesão" também foi usada como uma explicação para que alguns caminhoneiros nunca tenham saído com crianças e/ou adolescentes ("Não acho graça” ou "Meu negócio é as coroas. Trinta e oito, quarenta anos.”).

Por fim, destaquem-se as respostas que mencionam o respeito às próprias meninas/adolescentes como justificativa para não as abusarem. Nesse caso, os caminhoneiros tendem a identificá-las e compará-las com suas próprias filhas ou netas, como expresso nas seguintes frases: "Penso nas minhas meninas", "Eu olho como se fosse a minha filha..." e "Eu tenho neta com quinze anos já..."). Embora nessa questão em específico, a pergunta fosse sobre "por que nunca saiu com criança/adolescente?”, em outros momentos do questionário esse argumento também se fez presente. Especialmente entre os participantes que afirmaram já ter sido clientes do comércio sexual com crianças/adolescentes, muitos afirmaram que pararam de fazê-lo quando, por exemplo, uma filha ou neta nasceu. O respeito e a fidelidade à figura da esposa/companheira também foi mencionado ("Tenho família. Penso que não se faz com os outros o que não se quer pra gente.”).

\section{Considerações Finais}

A pesquisa em questão avança ao considerar a complexidade do fenômeno da exploração sexual comercial, a qual se configura a partir de uma conjuntura de fatores econômicos, políticos, sociais e legais. Nesse sentido, dá-se um passo à frente ao entender os condicionantes da ESCCA a partir da perspectiva desse grupo social. Circulando pelas estradas do nosso país e conhecendo de perto a realidade de exploração a que muitas crianças/adolescentes estão submetidas, os caminhoneiros representam uma fonte de informação privilegiada acerca de como a ESCCA vem se configurando. No entanto, em nenhum momento buscou-se rotular os caminhoneiros de abusadores/exploradores sexuais, contribuindo-se para o aumento do estigma social de uma categoria que tradicionalmente é vista com preconceito pela sociedade. 
Durante a realização das entrevistas, os relatos estiveram centrados muito mais na figura dos caminhoneiros como aqueles que presenciam a situação de ESCCA e que já saíram (ou não saíram) com crianças/adolescentes. Não houve maiores referências à participação "informal" dos caminhoneiros nas redes de exploração sexual, seja através do agenciamento ou do transporte das meninas de um lugar para outro do país sem que isso envolvesse o uso sexual da criança/adolescente para seu próprio prazer. Portanto, nessa pesquisa, a participação do caminhoneiro na exploração sexual mostrou-se bastante atrelada à situação de abuso sexual da criança/adolescente.

Ao dar voz aos caminhoneiros (abusadores e não abusadores), buscou-se contemplar a complexidade de fatores (econômicos, políticos, sociais e legais) envolvidos da situação de exploração sexual. O objetivo foi o de contribuir para a superação das velhas e maniqueístas dicotomias. Estas tendem a entender o abusador a partir de uma questão simplesmente moral (certo/errado; vilão/mocinho) e que pode ser abordada através, exclusivamente, de leis mais rigorosas e de maior controle policial (Santos, 2004).

Metodologicamente, esse trabalho também apresenta importantes contribuições. Inicialmente, porque propõe a compreensão da ESCCA a partir da perspectiva do abusador, quase sempre negligenciado nos estudos da área, centrados unicamente na perspectiva da vítima (Moura, 2006). Outros pontos positivos estão relacionados ao procedimento de coleta de dados, baseada na metodologia da inserção ecológica.

A inserção da equipe de pesquisa em postos e locais de parada desses caminhoneiros em quatro diferentes regiões do país, possibilitou o estabelecimento de uma relação de confiança entre entrevistadores e participantes, assim como uma maior aproximação a esse contexto. Nesse sentido, verificou-se in loco a "força" do fenômeno da ESCCA, às vistas de qualquer pessoa que esteja nos postos de gasolina e locais de parada dos caminhoneiros. A possibilidade de entrevistar 239 diferentes caminhoneiros de diferentes regiões do país e que possuem uma grande circulação pelas estradas brasileiras também foi um aspecto relevante da pesquisa. Não há nenhuma referência anterior de estudos nacionais sobre a temática da ESCCA que tenham sido realizados com abusadores, ou com caminhoneiros, tampouco com um número tão expressivo destes.

Alguns resultados obtidos podem ser melhor compreendidos ao se considerar a visão que os abusadores possuem sobre as crianças envolvidas na situação de exploração sexual. Ao serem indagados sobre a importância de certas atividades na vida de crianças e adolescentes, os caminhoneiros forneceram respostas aceitáveis socialmente, como "brincar e estudar" para as crianças e "namorar e ficar com os amigos" para os adolescentes. Contudo, em outros momentos, os participantes tendiam a "encurtar" e relativizar as faixas etárias correspondentes à infância e à adolescência. Este fato ocorreu, principalmente, em momentos nos quais os caminhoneiros relatavam histórias sobre o envolvimento deles ou de seus companheiros em relações sexuais com adolescentes.

Verifica-se, então, que este tipo de afirmação pode atuar como uma maneira de justificar o relacionamento sexual com crianças e adolescentes, numa tentativa de afirmar que mesmo sendo seres em nível de desenvolvimento diferente do deles, as crianças e adolescentes seriam seres sexuais. Este tipo de justificativa foi relatada por Ward e Keenan (1999) em estudos realizados com abusadores sexuais. Como conclusão, tem-se que os caminhoneiros usam justificativas semelhantes àquelas usadas por abusadores sexuais para legitimar o sexo entre adultos e crianças ou entre adultos e adolescentes. A visão sobre as crianças como seres sexuais foi constatada em outras respostas dos caminhoneiros. Quando indagados sobre os motivos que ocasionariam a atividade de exploração sexual infantil, a terceira resposta mais citada foi "elas gostam de sexo/têm prazer". Com esta resposta, pode-se notar que alguns caminhoneiros percebem as crianças como seres sexuais.

De fato, não se trata de afirmar que a criança e o adolescente são seres assexuados, que não possuem jogos e brincadeiras eróticas. Contudo, o que se deseja é demarcar a clara situação de desigualdade na qual o adulto (seja ele o agenciador, seja ele o cliente final) detém o poder de decidir como esta relação deve se estabelecer, impondo às crianças e ao adolescente suas vontades e desejos. O reconhecimento dessa relação de desigualdade é necessária para que não se alimente teorias que responsabilizem as vítimas, tais como a Teoria da Precipitação da Vítima, que afirma que crianças e adolescentes provocam seus abusadores, contribuindo assim para a ocorrência da situação de violência (Itenbi, 1998).

Vários outros resultados se relacionam com a visão da criança sendo um ser menos importante ou não possuindo status de pessoa (Day \& cols., 2003). Essa perspectiva é descrita por Safiotti (1989) como adultocentrismo. Quando indagados sobre os motivos que levam os homens a procurar sexo com crianças e adolescentes, os caminhoneiros responderam que isto ocorre, principalmente, porque eles teriam mais excitação e prazer. Aqui, um questionamento pode ser feito: e a vontade das crianças? Será que elas teriam alguma vontade frente a estas situações? Com esta resposta fornecida pelos participantes, pode-se concluir que o que mais importaria seria a vontade das pessoas que procuram os serviços sexuais infantis e não as vontades e/ou necessidades das crianças ou adolescentes envolvidas.

As respostas dadas sobre "por que não se deve fazer sexo com crianças?" também são elucidativas desta questão. Os principais motivos apontados foram: "evitar problemas com a justiça", "não tem tesão", "respeito a esposa/fidelidade"; "não teve oportunidade", "medo de doenças" e "medo de ser difamado/falta de coragem". Estas respostas, portanto, não refletem um respeito às necessidades e direitos das crianças e adolescentes, mas baseiam-se em uma "moralidade do medo", expressa no temor de ser punido pela polícia ou de contrair alguma doença sexualmente transmissível, por exemplo.

A pouca responsabilidade dos adultos frente às crianças exploradas sexualmente também pode ser notada em algumas questões. Ao responderem sobre os motivos pelos quais as crianças "se prostituíam", os participantes quase sempre relataram que a responsabilidade era da condição financeira das famílias, das próprias crianças, da falta da educação, entre outros motivos. Poucos caminhoneiros atentaram para o fato de haver um demanda ou um mercado para os "serviços sexuais" oferecidos pelas crianças, mercado este formado pelos próprios caminhoneiros e outros adultos. 
Essa resposta ilustra, por sua vez, a tendência desses caminhoneiros entrevistados de não perceberem a grande responsabilidade que este mercado ou demanda tem para a exploração sexual infantil. De fato, essa tendência de desresponsabilização parece ser característica não somente desse grupo social, mas de todo um contexto sócio-cultural pouco atento aos diversos condicionantes da exploração sexual comercial infantil. É muito mais freqüente na nossa sociedade, que o fenômeno da ESCCA esteja relacionado à culpabilização das crianças e adolescentes vítimas (elas "gostam de sexo, têm prazer, escolhem o caminho mais fácil") e, no máximo, à situação de pobreza em que estas crianças e adolescentes vivem. Além disso, entre os participantes, não há quase nenhuma referência aos prejuízos que a situação de abuso pode acarretar ao desenvolvimento dessas crianças e adolescentes. A percepção destas parece ser bastante coisificada e despersonalizada, à semelhança de uma mercadoria qualquer.

Atrelada a esta última questão, está uma outra: a visão da criança como responsabilidade apenas de sua família (Day \& cols., 2003). Assim, é possível compreender mais um motivo pelo qual os homens se sentiriam pouco responsáveis pela situação das crianças exploradas sexualmente. Eles não seriam responsáveis por ela, já que apenas sua família poderia tomar conta de seus filhos e filhas, e assim, resolver tal situação. De acordo com Londoño (1999), portanto, parece haver uma marcada diferença entre as "crianças de família" pertencentes ao círculo familiar dos caminhoneiros e as crianças exploradas. Enquanto às primeiras é assegurada a garantia de seus direitos, as segundas são vistas como um produto a ser comercializado, sem que haja a mínima proteção de seus direitos.

De acordo com Safiotti (1989), alguns condicionantes da exploração sexual comercial infantil são a desigualdade social e econômica (pobreza e racismo), assim como uma forte cultura de gênero machista e adultocêntrica. A presente pesquisa corrobora fortemente a análise dessa autora. No entanto, os resultados aqui destacados, ilustram a influência que a visão dos caminhoneiros entrevistados (abusadores ou não abusadores) acerca das crianças envolvidas na exploração sexual comercial pode ter sobre a formação da demanda para esse tipo de serviço. Nesse sentido, destaca-se a tendência dos caminhoneiros à desresponsabilização (de si próprios e de outros) diante das crianças e adolescentes abusadas, o seu pouco conhecimento e consideração dos direitos e características desenvolvimentais dessa população, assim como a tendência a atribuir o status de mercadoria, despersonalizando-as.

Por fim, acredita-se que a inclusão dessa perspectiva de análise acerca do fenômeno da ESCCA (visão dos caminhoneiros acerca das crianças e adolescentes exploradas) contribui para a elaboração de novas medidas de enfrentamento desse fenômeno. Trata-se de um amplo processo de mudança de cultura e valores. Nesse sentido, os próprios caminhoneiros, tanto aqueles que nunca fizeram programas sexuais com crianças e adolescentes, como aqueles que já abusaram, mas que não abusam mais, deram algumas importantes indicações.

Enquanto alguns destacaram a "cultura do medo", seja de doenças, assaltos ou da polícia, como sendo uma justificativa que orienta a sua conduta, outros tantos destacaram aquela que parece ser a perspectiva mais consistente, ética e eficaz. Esta, diz respeito à consideração das meninas (crianças e adolescentes) expostas nas vitrines do comércio sexual em postos e estradas de todo o nosso país, como "iguais/semelhantes" seus e de suas próprias esposas, filhas e netas. Em outras palavras, trata-se de respeitar, valorizar e resgatar a humanidade dessas crianças e adolescentes, fato que parece passar, inevitavelmente, pela consideração da humanidade também desses abusadores (Furniss, 1993).

De acordo com Santos (2004) é preciso haver uma mudança de pressupostos na forma de encarar o cliente da ESCCA. Ao invés de se insistir em rótulos, tais como de "pervertidos e pedófilos" e de se limitar a compreensão do fenômeno a uma questão de moral individual, necessário se faz o desvelamento das realidades econômicas, sociais, culturais e políticas envolvidas tanto na formação da demanda quanto da oferta do comércio sexual, conforme já foi destacado ao longo desse artigo. Destaca-se assim, que o uso do termo "abusador" passa a tomar outro significado a partir do momento que se encara o cliente da ESCCA de forma menos maniqueísta e passa-se a uma tentativa de compreensão dos condicionantes deste papel. Santos, por sua vez, avança nessa discussão quando inclui a figura do abusador na definição das ações de enfrentamento à exploração sexual comercial. De acordo com o autor, é necessário: 1) qualificar as intervenções em curso nos campos da prevenção, do atendimento educacional e assistencial às crianças e adolescentes sexualmente explorados através de uma diferenciação de estratégias para cada modalidade de abuso, perfil da vítima e abusador; 2) quebrar o ciclo de impunidade dos agentes envolvidos na ESCCA; e, por fim, e não menos desafiador, 3) ampliar o conhecimento e a intervenção com os clientes do sexo infanto-juvenil na linha reeducacional.

De fato, lidar na prática profissional com crianças e adolescentes vítimas de abuso (intra ou extra familiar) já é por si só complexo. Incluir nessa relação, os condicionantes econômicos característicos da situação de exploração sexual comercial parece tornar a situação ainda mais complexa. Incluir a figura do abusador nesse cenário, então... Um desafio e tanto! Esse artigo propôs-se, portanto, a dar um passo nesse sentido. Como pesquisadores e psicólogos assumimos que tão instigante e complexa que essa tarefa possa ser, ela é necessária e urgente.

\section{Referências}

Cecconello, A. M. \& Koller, S. H. (2003). Inserção ecológica na comunidade: Uma proposta metodológica para o estudo de famílias em situação de risco. Psicologia Reflexão e Crítica, $16,515-524$.

Conselho Federal de Psicologia. (2000). Resolução para pesquisas com seres humanos. Resolução $\mathrm{n}^{\circ}$ 016/2000, de 20 de dezembro de 2000. Brasília, DF.

Conselho Nacional de Saúde. (1996). Diretrizes e normas regulamentadoras de pesquisas envolvendo seres humanos. Resolução n 196/1996, de 16 de outubro de 1996.

Day, V. P., Telles, E. de B. L., Zoratto, P. H., Azambuja, M. R. F., Machado, D. A., Silveira, M. B., Debiaggi, M., Reis, M da G., Cardoso, R G. \& Paulo Blank (2003). Violência doméstica e suas manifestações. Revista de Psiquiatria do Rio Grande do Sul, 25, 9- 21. 
Davidson, J .C. \& Taylor, J. S. (1996). Child prostitution and sex tourism-Venezuela. Relatório de pesquisa para o World Congress Against Commercial Sexual Exploitation of Children da Unicef.

Davidson, J. C. (2001). Children in the Sex Trade in China. Estocolmo: Save the Children Sweden.

Desouza, E. R., Baldwin, J., Koller, S. H. \& Narvaz, M. G . (2004). A Latin American Perspective in the Study of Gender. Em M. Paludi, C. A. Paludi \& D. C. DeFour. (Orgs.), Praeger Guide to the Psychology of Gender (pp. 45-65). Ilinois: Greenwood Publishing Group.

ECA (1990). Estatuto da Criança e do Adolescente. Diário Oficial da União. Lei n. 8069, de 13 de julho de 1990, Brasília, DF.

Faleiros, E. T. S. (2000). Repensando os conceitos de violência, abuso e exploração sexual de crianças e adolescentes. Brasília: Thesaurus.

Faleiros, V. P. (2004). O fetiche da mercadoria na exploração sexual. Em R. M. C. Libório \& S. M. G. Souza (Orgs.), A exploração sexual de crianças e adolescentes no Brasil: Reflexões teóricas, relatos de pesquisa e intervenções psicossociais (pp. 51-72). Goiânia: Casa do Psicólogo/Editora da UCG.

Furniss, T. (1993). Abuso sexual da criança: uma abordagem multidisciplinar. Porto Alegre: Artmed.

Gomes, R. M., Minayo, M. C. S. \& Fontoura, H. A. (1999). A prostituição infantil sob a ótica da sociedade e da saúde. Revista de Saúde Pública, 33(2), 171-179.

Itenbi, I. (1998). Abuso sexual en las mejores famílias. Buenos Aires: Granica.

Leal, M. L. \& Leal, M. F. (2002). Pesquisa sobre tráfico de mulheres, crianças e adolescentes para fins de exploração sexual comercial no Brasil. Relatório Nacional - PESTRAF. Brasília: CECRIA.

Libório, R. M. C. (2003). Desvendando vozes silenciadas: Adolescentes em situação de exploração sexual. Tese de Doutorado, Pontifícia Universidade Católica de São Paulo, São Paulo.

Libório, R. M. C. (2004). Exploração sexual comercial infantojuvenil: Categorias explicativas e políticas de enfrentamento. Em R. M. C. Libório \& S. M. G. Souza (Orgs.), A exploração sexual de crianças e adolescentes no Brasil: Reflexões teóricas, relatos de pesquisa e intervenções psicossociais (pp. 19-50). Goiânia: Casa do Psicólogo/Editora da UCG.
Libório, R. M. C. \& Martinez, S.D.T. (2002). A construção de novos parâmetros conceituais sobre crianças e adolescentes em situação de exploração sexual. Intertemas, 6, 78-88.

Londoño, F. T. (1999). A origem do conceito de menor. Em M. Del Priori (Org.), História da criança no Brasil (pp. 129-145). São Paulo: Contexto.

Marques, H. M. de V. (2005). A voz do abusador: aspectos psicológicos dos protagonistas do incesto. Dissertação de Mestrado, Universidade Católica de Brasília. Brasília.

Moura, A. (2006). A criança na perspectiva do abusador sexual. Projeto de dissertação de Mestrado. Universidade Federal do Rio Grande do Sul, Porto Alegre.

Narvaz, M. G. (2005). Submissão e resistência: explodindo o discurso patriarcal da dominação feminina. Dissertação de Mestrado, Universidade Federal do Rio Grande do Sul, Porto Alegre:

Saffioti, H. (1989). Exploração sexual de crianças. Em M. A. Azevedo \& V. N. de A. Guerra (Orgs.), Crianças vitimizadas: a síndrome do pequeno poder (pp. 49-95). São Paulo: Iglu.

Santos, B. R. (2004). Contribuições para um balanço das campanhas de combate ao abuso e exploração sexual de crianças e adolescentes no Brasil. Em R. M. C. Libório \& S. M. G. Souza (Orgs.), A exploração sexual de crianças e adolescentes no Brasil: Reflexões teóricas, relatos de pesquisa e intervenções psicossociais (pp. 99-147). Goiânia: Casa do Psicólogo/Editora da UCG.

Ward, T. \& Keenan, T. (1999). Child molesters' implicit theories. Journal of Interpersonal Violence, 14, 821-838.

World Health Organization (Organização Mundial de Saúde) (1999). Child abuse \& neglect. Retirado em 18 de maio de 2006 de http://www.who.int/violence_injury_prevention/violence/ neglect/en/ 